\title{
Hedging Global and Country-Specific Geopolitical Risks With South Korean Stocks: A Predictability Approach
}

\author{
Tirimisiyu F. Oloko ${ }^{1} \otimes^{a}$, Abeeb O. Olaniran ${ }^{1}$ b Lukman A. Lasisi $^{1}$ c \\ ${ }^{1}$ Centre for Econometric \& Allied Research, University of Ibadan, Nigeria \\ Keywords: fqgls estimator, south korean stocks, geopolitical risk \\ https://doi.org/10.46557/001c.24418
}

\section{Asian Economics Letters}

Vol. 2, Issue 3, 2021

In this study, we examine the potential of South Korean stocks to hedge against global and country-specific geopolitical risks. A predictability approach with a feasible quasi generalized least square (FQGLS) estimator was employed. Our results reveal that global and country-specific geopolitical risks are good predictors of South Korean stock market returns. This implies that the South Korean stock market provides a good hedge against global and South Korean geopolitical risks.

\section{Introduction}

One of the reasons for holding stock assets is to hedge against potential risks. There is a growing literature on the hedging effectiveness of stock markets against risks. However, the majority of studies are focused on the hedging effectiveness of stock markets against country-specific domestic and economic risks, particularly inflation. While some studies find evidence of a positive relationship, which implies that stock returns are a good hedge for inflation risk (see Aktürk, 2016; Alagidede \& Panagiotidis, 2010; Kim \& Ryoo, 2011; Salisu et al., 2020), others find that stock returns do not hedge inflation risk (Khil \& Lee, 2000; Li et al., 2010).

In this study, we analyze the risk hedging potential of stock markets by examining the potential of the South Korean stock market to hedge global and country-specific geopolitical risks. The significance of geopolitical risks in investment or investment market performance has gained attention recently (Dos Santos et al., 2021; Guo et al., 2021). According to Caldara \& Iacoviello (2018), geopolitical risk is defined as the risk associated with terrorist acts, wars, and tensions between states that affect the normal and peaceful course of international relations. South Korea has a high expected political risk because, with its allies, South Korea has engaged in about six wars between 1950 and 2010. This includes the Korean War (1950-1953), the Vietnam War (1964-1973), the Korean DMZ Conflict (1966-1969), the Gulf War (1990-1991), the War in Afghanistan (2002-2014), and the Iraq War (2003-2008). ${ }^{1}$ Given the frequent involvement of South Korea in wars, holders of stock assets in this country may be exposed to geopolitical risks.

The main objective of this study is to examine the potential of the South Korean stock market to hedge against geopolitical risks. This is similar to the study by Guo et al. (2021), who investigated the roles of political risk and crude oil in the stock markets of China and the US using the quantile autoregressive distributed lag (QARDL) model. Our study extends the literature in several important respects. First, we consider the case of South Korea, which participates frequently in wars. Second, we examine the effect of not only country-specific geopolitical risks (as in Guo et al., 2021) but also global geopolitical risks. This follows the approach by Dos Santos et al. (2021), who investigated the impact of political risk on the currencies of emerging markets. They concluded that local political risk had a more significant impact on risk-premium volatility than global risk. Third, we employ the feasible quasi generalized least square (FQGLS) estimator (Westerlund \& Narayan, 2015). This is a predictability approach and a short-run modeling technique with the potential to account for the salient features of stock returns, such as persistence, endogeneity, and conditional heteroscedasticity (Olofin et al., 2020; Salisu, Swaray, et al., 2019). This method was chosen because investors in the stock market take investment decisions with the earliest available information (Erragragui et al., 2018). Additional analyses involve the examination of the hedging properties of the South Korean stock market against global health risks. This may be considered necessary due to the exposure of developed and developing stock markets to the COVID-19 pandemic (Iyke \& Ho, 2021; Salisu et al., 2021; Sharma, 2020).

\footnotetext{
a Corresponding author email: olokotrimicy@yahoo.com

b olaniranabeeb464@gmail.com

c abisoyelasisi2002@gmail.com

1 See: https://en.wikipedia.org/wiki/List of wars involving South Korea
} 
The remainder of this paper is as follow: Section II provides the data and the methodology; the empirical results are presented and discussed in Section III; Section IV concludes the paper.

\section{Data and Methodology}

The data used in this study are monthly data from February 1990 to July 2020 . This generates 261 observations. The analysis consists of three variables: Korean stock market index (KPS); geopolitical risk (GPR)-a measure of global political risk; and Korean geopolitical risk (KGPR)-a measure of country-specific geopolitical risk. KPS is expressed in returns computed as $100 \times \Delta \log \left(p_{t}\right)$ where $p_{t}$ is the stock market price index, obtained from investing.com. We use the geopolitical risk index by Caldara \& Iacoviello (2018), which is downloadable from the database of Matteo Iacoviello. $^{2}$ Other variables include: the equity market volatility due to infectious disease (EMV-ID) index by Baker et al. (2020) - a measure of global health risk; Chicago Board Options Exchange's volatility index [VIX]-a measure of global economic uncertainty (Salisu et al., 2021); and Korean economic policy uncertainty (KEPU). These variables are also obtained from the US Federal Reserve.

We rely on a bivariate predictive model for the response of the Korean stock returns to global and country-specific risks following the estimation procedure of Westerlund \& Narayan (2015) with the specification as follows:

$$
r_{t}=\alpha+\beta \eta_{t-1}+\phi\left(\eta_{t}-\rho_{0} \eta_{t-1}\right)+\varepsilon_{t}
$$

where $r_{t}$ is the South Korean stock return, $\alpha$ is the constant intercept, $\eta$ is the measure of risks, and $\varepsilon_{t}$ is the zero-mean idiosyncratic error term. The slope coefficient, $\beta$, shows the response of stock returns to the risk factors and measures the hedging potential of the South Korean stock market in this case. There are four possible outcomes: partial hedge, full hedge, superlative hedging performance, and no hedge. The South Korean stock market provides partial hedging for geopolitical, economic, and health risks if $0<\beta<1$ and full hedging if $\beta=1$, and possesses a superlative hedging property if $\beta>1$. However, if $\beta \leq 0$, it implies that the South Korean stock market does not provide hedging against global and country-specific geopolitical, economic, and health risks (Arnold \& Auer, 2015; Salisu et al., 2020; Salisu, Ndako, et al., 2019).

In order to resolve any concern with endogeneity bias resulting from the correlation between the predictor series and the error term, as well as any potential persistence effect, we follow the approach of Lewellen (2004) and Westerlund \& Narayan (2015). Thus, $\rho_{0}$ in Equation (1) above is the degree of persistence in the predictor series and is described as the bias-adjusted ordinary least squares (OLS) estimator of Lewellen (2004), which corrects for any persistence effect in the predictive model. The additional term $\phi\left(\eta_{t}-\rho \eta_{t-1}\right)$ corrects for any endogeneity bias resulting from the correlation between $\eta$ and $\varepsilon_{t}$, the error term, as well as any inherent unit root problem in them. In addition, to resolve the issue of conditional heteroscedasticity in the error term, we pre-weight all the data with the inverse of the standard deviation $\left(\frac{1}{\widehat{\sigma_{t}^{2}}}\right)$ obtained from a typical GARCH-type model and thereafter estimate the resulting equation with the OLS (Westerlund \& Narayan, 2015).

Finally, we employ a pair-wise forecast measure, the Clark \& West (2007) test, which helps to test whether the forecast error of the model outperforms the benchmark model. Furthermore, both the in-sample and out-of-sample performance of the predictive models for stock returns are evaluated using a 50:50 data split while the forecast analysis is rendered for multiple out-of-sample (10-month, 20-month, and 30-month) ahead forecast horizons.

\section{Results and Discussion}

Table 1 presents the predictability results for the relationship between the South Korean stock market and the global and country-specific geopolitical risks including other relevant risks such as health and economic risks. Our results show that the South Korean stock market can significantly hedge against global and South Korean geopolitical risks. As the slope coefficient for both global and country-specific geopolitical risks ranges between zero and one, it suggests that the South Korean stock market can only provide partial hedging for both global and country-specific geopolitical risks. However, as the hedging effectiveness coefficient is higher for country-specific geopolitical risk compared to the global geopolitical risk, the South Korean stock market may hedge domestic geopolitical risk better than the global geopolitical risk. This result is similar to that of Dos Santos et al. (2021), who concluded that local political risk had a more significant impact on risk-premium volatility than global risk (see also Demiralay \& Kilincarslan, 2019). By implication, investors may not need to divest out of the South Korean stock market in fear of global and/ or South Korean geopolitical risks.

In addition, the predictability results show that the South Korean stock market provides partial hedging against global economic risk as the global economic uncertainty index (VIX) is positive and statistically significant. However, the coefficient is negative for global health risk and South Korean economic risk (KEPU). This suggests that the South Korean stock market also has the potential to hedge against global economic risk better than against global health and domestic economic risks. This result partially contrasts with that of Salisu \& Vo (2020), who find that health news is a good predictor of stock market performance.

Furthermore, we evaluate the in-sample and out-of-sample forecast performance of our risk-based predictive model (Equation (1)) vis-à-vis the historical average model. For the out-of-sample forecast evaluation, we use $50 \%$ of the data, while we consider 10-month, 20-month, and 30-month ahead forecast horizons. Table 2 presents the in-sample and out-of-sample forecast performance of our risk-based predictive model. The result shows that countryspecific geopolitical risk and country-specific economic risk 
Table 1. Predictability results for South-Korean stock

\begin{tabular}{|c|c|c|c|}
\hline \multicolumn{2}{|c|}{ Global risk } & \multicolumn{2}{|c|}{ Country-specific risk } \\
\hline GPR & $0.09^{* * *}$ & KGPR & $0.16^{* * *}$ \\
\hline & $(0.02)$ & & $(0.05)$ \\
\hline \multirow[t]{2}{*}{ EMV-ID } & -0.66 & KEPU & $-0.05^{* *}$ \\
\hline & (0.89) & & $(0.02)$ \\
\hline \multirow[t]{2}{*}{ VIX } & $0.59^{* * *}$ & - & - \\
\hline & $(0.16)$ & - & - \\
\hline
\end{tabular}

This table shows the predictability results for South-Korean stock. GPR, EMV-ID and VIX represent global geo-political risk, equity market volatility and volatility index, respectively. Variables KGPR and KEPU, on the other hand, are Korean geo-political risk and Korean economic policy uncertainty, respectively. The symbols $* * * * * *$ and $*$ represent $1 \%, 5 \%$ and $10 \%$ significance levels, respectively. Values in parentheses represent standard errors.

Table 2. In-sample and out-of-sample forecast evaluation results for Clark and West (2007)

\begin{tabular}{|c|c|c|c|c|c|}
\hline \multicolumn{6}{|c|}{ In-sample } \\
\hline \multicolumn{2}{|c|}{ Global risk } & \multicolumn{2}{|c|}{ Country-specific risk } & \multirow[b]{2}{*}{-} & \multirow[b]{2}{*}{-} \\
\hline GPR & 6.10 & $K G P R$ & $16.02^{* *}$ & & \\
\hline & {$[0.71]$} & & {$[1.67]$} & - & - \\
\hline \multirow[t]{2}{*}{ EMV-ID } & 4.95 & KEPU & $37.10^{* * *}$ & - & - \\
\hline & [0.88] & & {$[3.25]$} & - & - \\
\hline \multirow[t]{2}{*}{ VIX } & $23.94^{* * *}$ & - & - & - & - \\
\hline & [2.12] & - & - & - & - \\
\hline \multicolumn{6}{|c|}{ Out-of-sample } \\
\hline \multicolumn{3}{|c|}{ Global risk } & & \multicolumn{2}{|c|}{ Country-specific risk } \\
\hline & GPR & EMV & VIX & $K G P R$ & KEPU \\
\hline \multirow[t]{2}{*}{$h=10$} & 6.20 & 3.56 & $23.07^{* * *}$ & $16.03^{* *}$ & $35.59^{* * *}$ \\
\hline & {$[0.75]$} & {$[0.64]$} & {$[2.10]$} & [1.73] & [3.20] \\
\hline \multirow[t]{2}{*}{$h=20$} & 5.56 & 3.58 & $22.68^{* * *}$ & $15.88^{* *}$ & $34.87^{* * *}$ \\
\hline & [0.69] & [0.66] & {$[2.12]$} & {$[1.76]$} & [3.22] \\
\hline \multirow[t]{2}{*}{$h=30$} & 5.11 & 5.46 & $20.76^{* * *}$ & $15.10^{* *}$ & $36.62^{* * *}$ \\
\hline & {$[0.67]$} & {$[1.00]$} & {$[2.02]$} & {$[1.77]$} & [3.54] \\
\hline
\end{tabular}

This table shows the in-sample and out-of-sample forecast evaluation results for Clark \& West (2007). RMSE is the root mean squared error, and it is the version of Clark \& West (2007)), which adjusts the difference in mean squared prediction errors to account for the additional predictors in the model. Symbols $*$ ***** and $*$ represent $1 \%, 5 \%$ and $10 \%$ significance levels, respectively. Values reported in square brackets are the $\mathrm{t}$-statistics. For the Clark \& West test, the null hypothesis of a zero coefficient is rejected if this statistic is greater than +1.282 (for a one sided 0.10 test), +1.645 (for a one sided 0.05 test), and +2.00 (for a one sided 0.01 test) (see Clark \& West, 2007).

enhance the in-sample and out-of-sample forecast performance of the South Korean stock market. This is apparent as our risk-based predictive models for country-specific geopolitical and economic risks outperform the historical average model. Also, we find that our risk-based predictive models with global geopolitical and health risks do not outperform the historical average model in-sample and out-ofsample, implying that geopolitical and health risks are not important in forecasting the South Korean stock market. Global economic uncertainty was, however, found to play a significant role in predicting the performance of the South Korean stock market.

\section{Conclusion}

In this study, we examine the potential of South Korean stocks to hedge against global and country-specific geopolitical risks. Other stock market-related risks, such as economic and health risks, are also considered. We employed a predictability approach with the FQGLS estimator. Our results reveal that the South Korean stock market can significantly hedge against global and South Korean geopolitical risks. This implies that investors need not divest from the South Korean stock market in fear of global and/or South Korean geopolitical risks. Furthermore, we find that country-specific geopolitical risk and country-specific economic risk enhance the in-sample and out-of-sample forecast performance of the South Korean stock market. However, our 
risk-based predictive models with global geopolitical and health risks do not outperform the historical average model in-sample and out-of-sample, implying that accounting for geopolitical and health risks is not important in forecasting the South Korean stock market.
Submitted: May 01, 2021 AEST, Accepted: May 20, 2021 AEST 


\section{REFERENCES}

Aktürk, H. (2016). Do stock returns provide a good hedge against inflation? An empirical assessment using Turkish data during periods of structural change. International Review of Economics \& Finance, 45, 230-246. https://doi.org/10.1016/j.iref.2016.06.00 $\underline{2}$

Alagidede, P., \& Panagiotidis, T. (2010). Can common stocks provide a hedge against inflation? Evidence from African countries. Review of Financial Economics, 19(3), 91-100. https://doi.org/10.1016/j.rfe.2010.04.0 $\underline{02}$

Arnold, S., \& Auer, B. R. (2015). What do scientists know about inflation hedging? The North American Journal of Economics and Finance, 34, 187-214. http s://doi.org/10.1016/j.najef.2015.08.005

Baker, S. R., Bloom, N., Davis, S. J., Kost, K., Sammon, M., \& Viratyosin, T. (2020). The unprecedented stock market reaction to COVID-19. The Review of Asset Pricing Studies, 10(4), 742-758. https://doi.org/10.109 3/rapstu/raaa008

Caldara, D., \& Iacoviello, M. (2018). Measuring geopolitical risk. FRB International Finance Discussion Paper, 1222. https://doi.org/10.17016/ifdp.2018.1222

Clark, T. E., \& West, K. D. (2007). Approximately normal tests for equal predictive accuracy in nested models. Journal of Econometrics, 138(1), 291-311. https://doi.o rg/10.1016/j.jeconom.2006.05.023

Demiralay, S., \& Kilincarslan, E. (2019). The impact of geopolitical risks on travel and leisure stocks. Tourism Management, 75, 460-476. https://doi.org/10.1016/j.t ourman.2019.06.013

Dos Santos, M. B. C., Klotzle, M. C., \& Pinto, A. C. F. (2021). The impact of political risk on the currencies of emerging markets. Research in International Business and Finance, 56, 101375.

Erragragui, E., Hassan, M. K., Peillex, J., \& Khan, A. N. F. (2018). Does ethics improve stock market resilience in times of instability? Economic Systems, 42(3), 450-469. https://doi.org/10.1016/j.ecosys.2017.09.003

Guo, Y., Li, J., Li, Y., \& You, W. (2021). The roles of political risk and crude oil in stock market based on quantile cointegration approach: A comparative study in China and US. Energy Economics, 97, 105198. http s://doi.org/10.1016/j.eneco.2021.105198

Iyke, B. N., \& Ho, S.-Y. (2021). Exchange rate exposure in the South African stock market before and during the COVID-19 pandemic. Finance Research Letters, 102000. https://doi.org/10.1016/j.frl.2021.102000

Khil, J., \& Lee, B.-S. (2000). Are common stocks a good hedge against inflation? Evidence from the Pacificrim countries. Pacific-Basin Finance Journal, 8(3-4), 457-482. https://doi.org/10.1016/s0927-538x(00)0001 9-6
Kim, J. H., \& Ryoo, H. H. (2011). Common stocks as a hedge against inflation: Evidence from century-long US data. Economics Letters, 113(2), 168-171. https://d oi.org/10.1016/j.econlet.2011.07.003

Lewellen, J. (2004). Predicting returns with financial ratios. Journal of Financial Economics, 74(2), 209-235. https://doi.org/10.1016/i.jfineco.2002.11.002

Li, L., Narayan, P. K., \& Zheng, X. (2010). An analysis of inflation and stock returns for the UK. Journal of International Financial Markets, Institutions and Money, 20(5), 519-532. https://doi.org/10.1016/j.intfi n.2010.07.002

Olofin, S. O., Oloko, T. F., Isah, K. O., \& Ogbonna, A. E. (2020). Crude oil price-shale oil production nexus: a predictability analysis. International Journal of Energy Sector Management. https://doi.org/10.1108/ijesm-0 5-2019-0004

Salisu, A. A., Akanni, L. O., \& Vo, X. V. (2021). Volatility spillovers and hedging effectiveness between health and tourism stocks: Empirical evidence from the US. International Review of Economics \& Finance, 74, 150-159. https://doi.org/10.1016/j.iref.2021.02.005

Salisu, A. A., Ndako, U. B., \& Oloko, T. F. (2019). Assessing the inflation hedging of gold and palladium in OECD countries. Resources Policy, 62, 357-377. http s://doi.org/10.1016/i.resourpol.2019.05.001

Salisu, A. A., Raheem, I. D., \& Ndako, U. B. (2020). The inflation hedging properties of gold, stocks and real estate: A comparative analysis. Resources Policy, 66, 101605. https://doi.org/10.1016/j.resourpol.2020.101 605

Salisu, A. A., Swaray, R., \& Oloko, T. F. (2019). Improving the predictability of the oil-US stock nexus: The role of macroeconomic variables. Economic Modelling, 76, 153-171. https://doi.org/10.1 016/j.econmod.2018.07.029

Salisu, A. A., \& Vo, X. V. (2020). Predicting stock returns in the presence of COVID-19 pandemic: The role of health news. International Review of Financial Analysis, 71, 101546. https://doi.org/10.1016/i.irfa.20 20.101546

Sharma, S. S. (2020). A note on the Asian market volatility during the COVID-19 pandemic. Asian Economics Letters, 1(2), 17661. https://doi.org/10.4655 7/001c.17661

Westerlund, J., \& Narayan, P. (2015). Testing for predictability in conditionally heteroskedastic stock returns. Journal of Financial Econometrics, 13(2), 342-375. https://doi.org/10.1093/jifinec/nbu001 